\title{
Principais fatores de risco para a depressão puerperal: revisão de literatura.
}

\author{
Ana Paula De Costa Ferro1; Maria Alice De Costa Ferro²
}

\section{Resumo}

Introdução: o pós-parto é o período de maior probabilidade para o aparecimento de transtornos psiquiátricos, afetando a paciente, o bebê e as relações familiares, como baixa adesão ao aleitamento e negligência no autocuidado. A depressão pós-parto (DPP) pode ocorrer nos 12 meses seguintes ao parto, com exacerbação dos sintomas no primeiro semestre. Caracterizada por: humor deprimido, perda de prazer e de interesse nas atividades, alterações de apetite e/ou peso, alteração de sono, sensação de fadiga, sentimento de inutilidade, culpa, dificuldade de concentração ou de tomar decisões e até pensamentos de morte ou de suicídio. Método: revisão sistemática de artigos publicados entre 2010 e 2015 nas bases de dados Lilacs e SciELO. Os seguintes Descritores em Ciências da Saúde (DeCS) foram considerados: transtornos puerperais, período pós-parto e depressão. Resultados: foram encontrados 1.267 estudos; desses, 14 foram selecionados com base nos critérios de inclusão. Como principais fatores de risco associados à DPP verifica-se: ausência de suporte social (suporte emocional oferecido pela família e pelos amigos à puérpera); presença de problemas conjugais; condições socioeconômicas desfavoráveis (baixa escolaridade da mãe, baixa renda familiar); histórico de depressão prévia; presença de alterações emocionais no período pré-menstrual; estresse gestacional (temores em relação ao parto e ao corpo); complicações obstétricas durante gravidez/parto; e necessidade de internação pediátrica. Conclusões: ainda que os estudos utilizados tenham diferenças

\footnotetext{
${ }^{1}$ Graduanda em Medicina pela Universidade Federal da Fronteira Sul Campus Passo Fundo. Email: ana.decostaferro@hotmail.com

${ }^{2}$ Graduanda em Medicina pela Universidade Federal da Fronteira Sul Campus Passo Fundo. Email: m.alicedecostaferro@ymail.com
} 
metodológicas e amostrais, fica evidente a complexidade dos fatores preditivos à DPP. Além disso, mesmo que sua frequência atinja valores entre $10 \%$ a $20 \%$ (conforme método diagnóstico e fatores de risco associados), o assunto costuma ser silenciado, seja pelos sentimentos de vergonha e inadequação das puérperas em manifestar mal-estar diante do neonato, seja pelo desconhecimento deste fenômeno psíquico pelas equipes de saúde. Portanto reconhecer a frequência do problema e identificar os grupos mais vulneráveis, possibilita a elaboração de estratégias que visem a prevenção, o diagnóstico precoce e o tratamento adequado da DPP.

Palavras Chave: transtornos puerperais; período pós-parto; depressão 